\title{
Effect of Chitosan and its Derivatives on the Mechanical and Electrical Properties of Paper Sheets
}

\author{
A. M. A. Nada, Mohamed El-Sakhawy, Samir Kamel, M. A. M. Eid" \\ and Abeer M. Adel \\ Cellulose and Paper Dept., National Research Center, \\ Dokki, Cairo, Egypt. \\ "Microwave Physics Dept., National Research Center, Dokki, Cairo, \\ Egypt.
}

The presented studies are focused on the dependence of paper sheet strength properties on the composition of additives, chitosan, cyanoethyl and carboxymethyl chitosan. Chitosan and its derivatives achieve an improvement in the strength properties of unagged and agged paper sheets. Also, cyanoethyl chitosan improves the dielectric properties of the treated paper sheets. The dielectric study was carried out over a frequency range from $100 \mathrm{~Hz}$ to 100 $\mathrm{kHz}$ at temperature range from 20 to $140^{\circ} \mathrm{C}$. The variation of permittivity $\mathcal{E}^{\prime}$ versus cyanoethyl chitosan content at three different temperatures shows an interesting point at concentration $\approx 0.3 \%$. The variation of $\varepsilon^{\prime}$ with temperature is explained in the view of the polar groups' mobility. The variation of $\varepsilon^{\prime \prime}$ versus the applied frequency is fitted by a superposition of Fröhlich and Havriliak-Negami functions in addition to the conductivity term. These functions could be ascribed to be due to the Maxwell-Wagner effect and the orientation of the large aggregates formed by the addition of chitosan to the paper sheet. Infrared spectroscopy of the chitosan and its derivatives were also examined. New bands were found at $2225 \mathrm{~cm}^{-1}$ and at $1710 \mathrm{~cm}^{-1}$ for cyano- and carboxy groups in the cyanoethyl and carboxymethyl chitosan respectively.

\section{Introduction:}

Paper fiber is held together by hydrogen bonds [1]. These bonds affect the distance between the separate cross-linking fibers. Water molecules play an important role in the interfiber linkage. A large excess of free water, however, causes weakness of wet strength in paper sheets and paper board [2]. To improve the wet strength of the paper sheets, a number of resins and polymeric 
materials have been used such as urea, phenol- and melamine- formaldehyde resins [3] in addition to polyacrylamide, polymethyl methacrylate [4,5], vinyl acetate - vinyl chloride copolymer [6]. Moreover, some other polymers were used to increase the resistance of paper sheets toward water absorption such as perfluorated urethane mixture [7].

On the other hand, some polymers were used for treatment of paper sheets to decrease its influence to the photo yellowing [8]. These polymers usefully used to treat the old paper documents [9] and enable the interfiber bonding area to remain chemically linked in the presence of water. Otherwise, these polymeric materials can be used as additives during paper sheets formation or as solution to dip the paper sheet in it. The surface modification of cellulose fiber [10] permits the direct formation of hydrogen bonds between the fiber surface areas. The feature of good strength additives must be (a) soluble in water based system, (b) substantive to cellulose so that its retention is efficient, (c) compatible with cellulose, (d) film forming to offer adhesive resistance, (e) contain a functional group capable of ionic or covalent bonding with paper fiber.

The Chitosan (CS) is known to be non-toxic and odourless. So much interest has been paid to its industrial applications in the past decade [11,12]. In addition, chitosan is expected to be useful in the development of composite materials such as blends or alloys with other polymers, since chitosan has many functional groups $[13,14]$, such as hydroxyls, amines and amides.

Dielectric measurements are considered to be powerful tools for studying the molecular behaviour of polymeric materials, for such reason it attracts many authors to investigate the dynamics of cellulosic and polymer materials by using dielectric technique [15-18].

In the present work, chitosan and its derivatives, cyanoethyl and carboxymethyl chitosan are used as additives to cellulose fiber during the formation of paper sheet or as solution for dipping the paper sheet in it. Infrared spectra of chitosan and its derivatives are detected. The dielectric properties as well as the mechanical properties of the produced paper sheets are also investigated. 


\section{Experimental:}

\subsection{Materials:}

Unbleached Kraft bagasse pulp, delivered from Edfo Paper Mill (Upper Egypt) was used in this work. Chitosan, commercial grade with $85 \%$ degree of deacetylation was used. Acrylonitrile (AN) and Monochloroacetic acid of analytical pure grades were used.

\subsection{Cyanoethylation of Chitosan:}

$5 \mathrm{~g}$ of chitosan were suspended in $250 \mathrm{ml} 30 \% \mathrm{NaOH}(\mathrm{w} / \mathrm{v})$, then $150 \mathrm{ml}$ AN were added to the chitosan solution and refluxed for 6 hour. The produced cyanoethyl chitosan was precipitated by methanol, filtered by using a $\mathrm{G}_{2}$ sintered glass funnel and washed with methanol and dried in a vacuum oven at $55{ }^{\circ} \mathrm{C}$ for 8 hours to give $8 \mathrm{~g}$ dried cyanoethyl chitosan.

\subsection{Carboxymethylation of Chitosan:}

Carboxymethylation was carried out by stirring $5 \mathrm{~g}$ chitosan in $100 \mathrm{ml}$ $20 \% \mathrm{NaOH}(\mathrm{w} / \mathrm{v})$ for 15 minutes. $15 \mathrm{~g}$ Monochloroacetic acid was added dropwise to the reaction medium and the reaction continued for 2 hours at $40{ }^{\circ} \mathrm{C}$ with stirring. Then the reaction mixture was neutralized with $10 \%$ acetic acid, poured into an excess of $70 \%$ methanol, filtered by using a $\mathrm{G}_{2}$ sintered funnel and washed with methanol. The produced carboxymethyl chitosan was dried in a vacuum at $55^{\circ} \mathrm{C}$ for 8 hours to give $6.5 \mathrm{~g}$ dried carboxymethyl chitosan.

\subsection{Infrared spectroscopy:}

Infrared spectroscopy of chitosan and its derivatives was carried out by using $\mathrm{KBr}$ disc technique using JASCO FT/IR 3006 (Fourier Transform Spectrometer).

\subsection{Hand sheet formation:}

Pulp was beaten to $40{ }^{\circ} \mathrm{SR}$ in a Jokro mill beater according to the Swedish Standard Method (SCA). Hand sheets of basis weight $68 \mathrm{~g} / \mathrm{m}^{2}$ were formed and different concentrations of chitosan, cyanoethyl or carboxymethyl chitosan solution (dissolved in $5 \%$ acetic acid) were added in a mixer.

In another trial; paper sheets were dipped in different concentrations of chitosan solution and also its derivatives for 30 second. After dipping, the paper sheets were pressed between two filter paper sheets to remove the excess polymer, and then dried on drum at $105^{\circ} \mathrm{C}$ for 2 hours. 
Untreated and treated paper sheets were aged at $140{ }^{\circ} \mathrm{C}$ for 2 hours.

The following properties were got according to the relevant Tappi Standards (19):

- Grammage i.e. weight of $1 \mathrm{~m}^{2}$, from it the retained amount $\left(\mathrm{g} / \mathrm{m}^{2}\right)$ of chitosan or its derivatives on paper sheets were calculated.

Tensile strength (p) x 6.67 x 10000

- Breaking length $(\mathrm{m})=$

Grammage (g)

Tear strength $[\mathrm{mN}]$ x 16 (pendulum factor) x 100

- Tear factor

$=\frac{\text { Tear strength }[\mathrm{mN}] \times 16 \text { (pendulum factor) } \times 100}{\text { Number of testes sheets } x \text { Grammage }(\mathrm{g})}$

\subsection{Dielectric measurements:}

Dielectric measurements were carried out in the frequency range of 100 $\mathrm{Hz}$ up to $100 \mathrm{kHz}$ using an LCR meter type AG-411 B (Ando electric Ltd. Japan). The capacitance " $\mathrm{C}$ " and the loss tangent " $\tan \delta$ " were obtained directly from the bridge from which the permittivity " $\varepsilon$ " and dielectric loss " $\varepsilon$ "' were calculated. A guard ring capacitor of the type NFM/5T Wiss Tech. Werkstatten (WTW) GMBH Germany was used as a measuring cell. The cell was calibrated by using standard materials [20] and the experimental error in $\varepsilon^{\prime}$ and $\varepsilon^{\prime \prime}$ was found to be $\pm 3 \%$ and $\pm 5 \%$ respectively. The temperature of the cell was controlled to within $\pm 0.1{ }^{\circ} \mathrm{C}$ using an ultra thermostat through a jacket surrounding the cell.

\section{Results and Discussion:}

\subsection{Infrared spectra:}

Chitosan undergoes different reactions to produce derivatives used as additives in paper sheets. Cyanoethyl and carboxymethyl chitosan were prepared from chitosan. Infrared spectroscopy was used to follow the chemical structure of the produced derivatives. From infrared spectra Fig. (1), it is interesting to notice that chitosan and its derivatives have band (shoulder) appeared at $3063 \mathrm{~cm}^{-1}$ due to $\mathrm{NH}_{2}$ stretching vibration [21]. On the other hand the relative absorbance of the band at $3400 \mathrm{~cm}^{-1}$ which is characteristic to $\mathrm{OH}$ group (ratio of the absorbance at the subscript wave number $3400 \mathrm{~cm}^{-1}$ to the absorbance of wave number at $1325 \mathrm{~cm}^{-1}$ which corresponds to the $\mathrm{CH}$ rocking of the ring) [22] is higher than that of cyanoethyl carboxymethyl chitosan (Table 1). This can be attributed to the occupation of the $\mathrm{OH}$ group of chitosan with cyanoethyl or carboxymethyl group. 


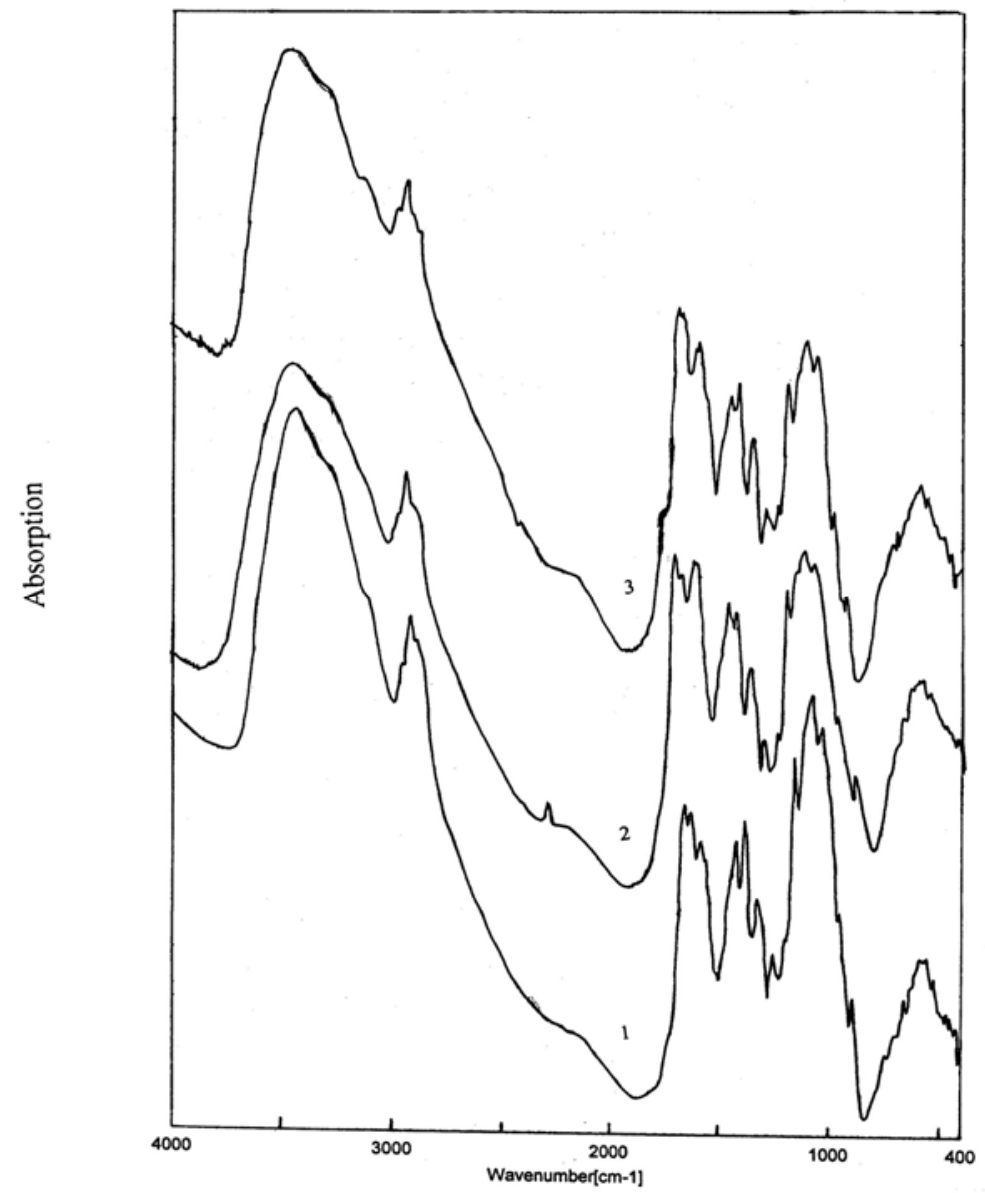

Fig. (1): Infrared Spectroscopy of (1) Chitosan, (2) Cyanoethyl Chitosan and (3) Carboxymethyl Chitosan.

Table (1): FTIR Characteristic of Chitosan and its Derivatives

\begin{tabular}{|c|c|c|}
\hline Material & $\begin{array}{c}\text { Wave number }\left(\mathrm{cm}^{-1}\right) \\
\text { of OH group }\end{array}$ & Relative absorbance \\
\hline Chitosan & 3398 & 1.80 \\
\hline Cyanoethyl chitosan & 3392 & 1.64 \\
\hline Carboxymethyl chitosan & 3390 & 1.60 \\
\hline
\end{tabular}




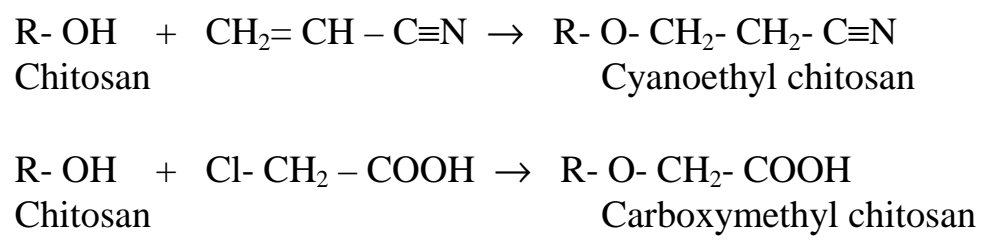

On the other hand a new band appeared at $2223 \mathrm{~cm}^{-1}$, characteristic for $\mathrm{C} \equiv \mathrm{N}$ stretching vibration in cyanoethyl chitosan. A new band also appeared at $1715 \mathrm{~cm}^{-1}$, characteristic for CO of carboxylic group.

Crystallinity index of cyanoethyl chitosan (band intensity at 1425 / band intensity at $900 \mathrm{~cm}^{-1}$ ) is higher than that in case of chitosan itself. This can be confirmed by the shift of the $\mathrm{OH}$ band at $3422 \mathrm{~cm}^{-1}$ to lower wave number $3415 \mathrm{~cm}^{-1}$ i.e. the hydrogen bond intensity of chitosan was increased. In case of carboxymethyl chitosan a new band was formed at $1715 \mathrm{~cm}^{-1}$ which is related to carbonyl group of the carboxymethyl group. On the other hand, the crystallinity index of the produced carboxymethyl chitosan is lower than that in case of chitosan and cyanoethyl chitosan.

\subsection{Chitosan and its derivatives as additives during sheet formation:}

The solutions of chitosan and its derivatives were added during paper sheet formation with different percentages. From Figs. (2\&3) It is clear that, the addition of chitosan $(0.05-1 \%$ by weight) has been shown to be effective as mediator of fiber-water interaction in paper, improving both breaking length and tear factor of the produced paper sheet. The presence of basic groups on every ring makes chitosan soluble in dilute aqueous acidic solution which makes it substantive to anionic pulp paper, this increases the covalent crosslinking between paper fibers [23]. Also, chitosan contains a functional group capable of ionic or covalent bonding with the paper fiber surface during the paper making process. This produces film to offer adhesive resistance to rapture. On the other hand, chitosan should be compatible with cellulose surface so that it does not disrupt covalent hydrogen bonding. So, for the previous reasons, addition of chitosan during paper making increases the mechanical properties of the produced paper. From Fig. (2), it is clear that, increasing the amount of added chitosan higher than $0.3 \%$, the breaking length decreases. This may be due to the increase of the intensity of the produced film and causes a hardens of the fiber and consequently the cracking of the produced paper sheet increases.

From Figs. (4 -7), addition of chitosan or its derivatives during paper sheets formation, causes an improvement of the mechanical properties. The improvement obtained by addition of chitosan derivatives is less than that 
produced by the addition of chitosan itself. This may be due to the cross-linking between the paper sheet fibers, produced by chitosan derivatives being less intensive than that produced by chitosan itself. On the other hand the improvement which occurred due to carboxymethyl chitosan is lower than that resulting from cyanoethyl chitosan.

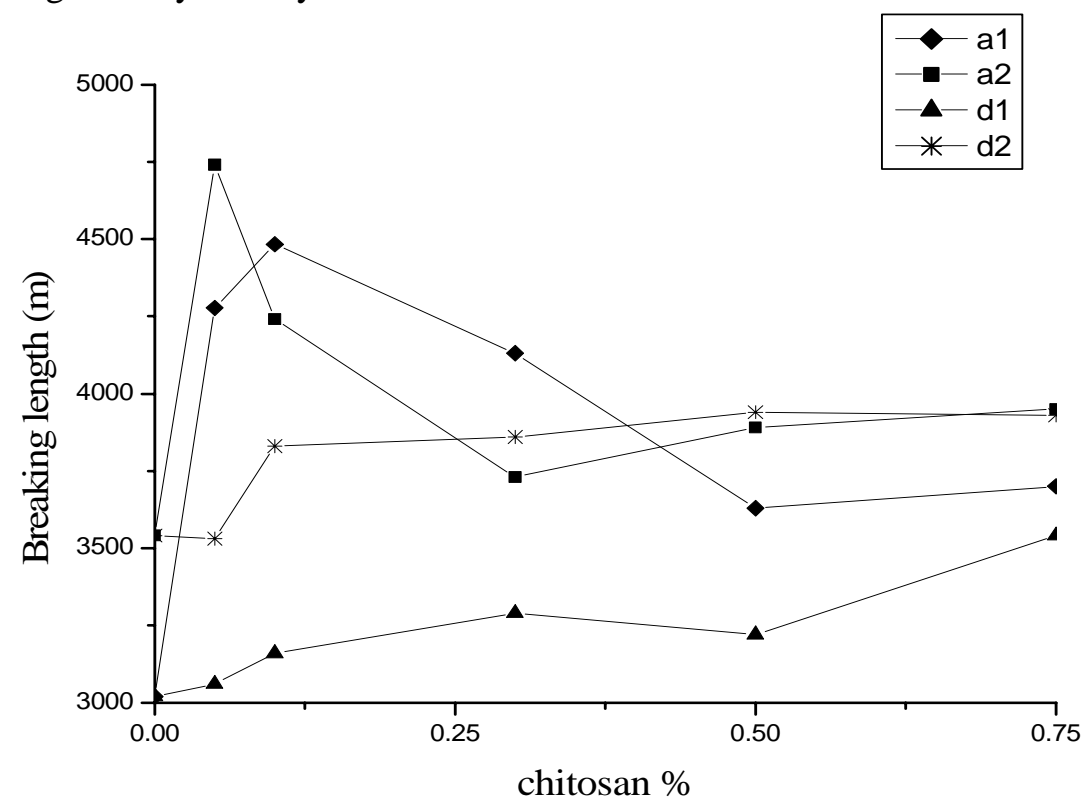

Fig. (2): Effect of chitosan \% on breaking length before and after aging.

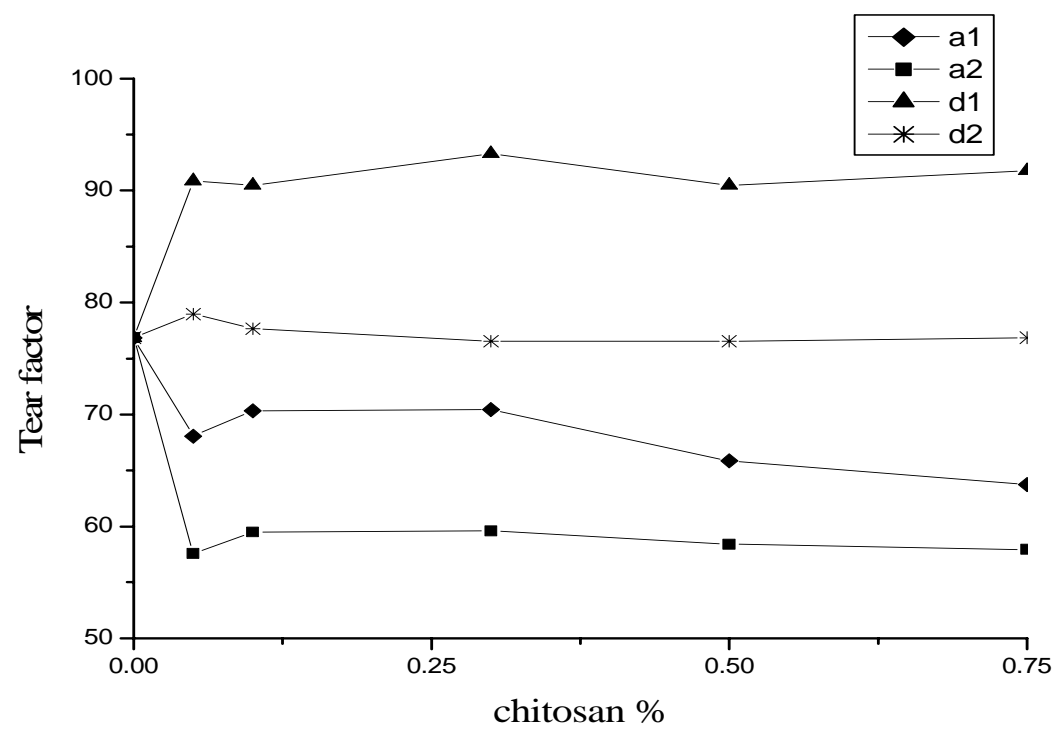

Fig. (3): Effect of chitosan \% on tear factor before and after aging. 


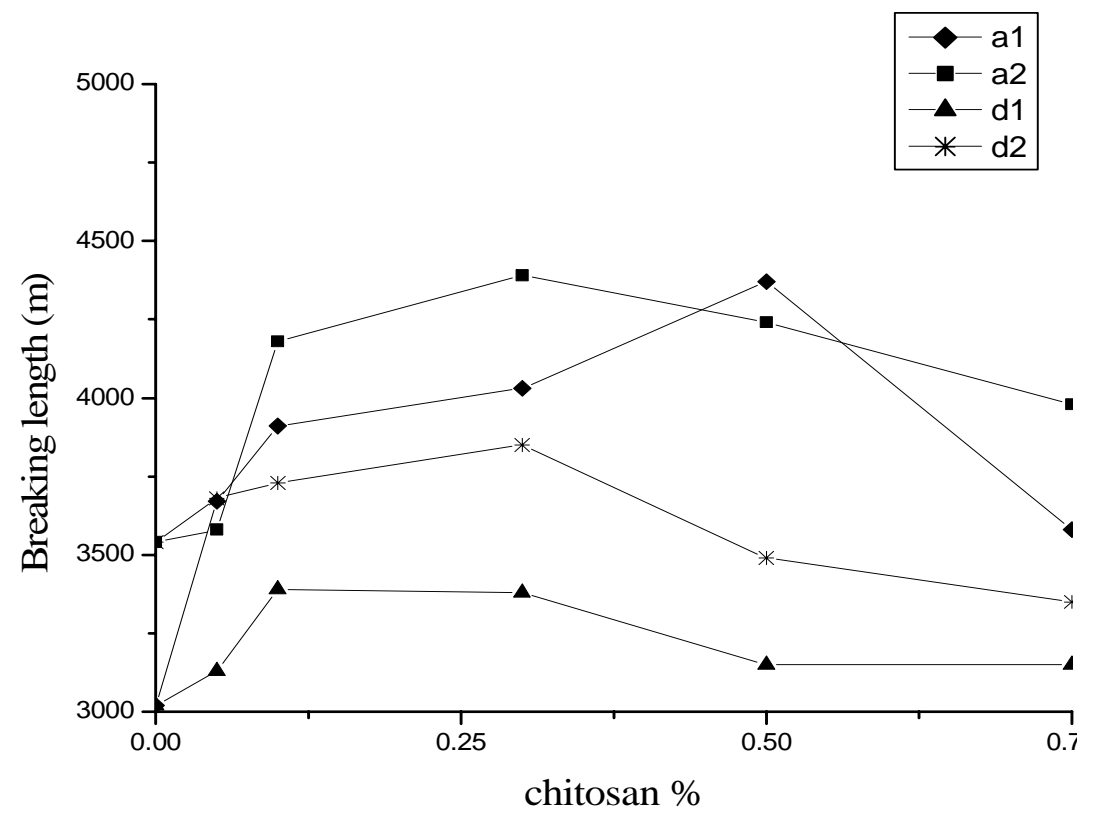

Fig. (4): Effect of Cyanoethyl chitosan \% on breaking length before and after aging.

Addition of mixture of cyanoethyl and carboxymethyl chitosan improves the mechanical properties of the produced paper sheets (see Table (2)). Increasing the ratio of carboxymethyl cellulose in the mixture, reduces the improvement of the mechanical properties of the paper sheets although it is still higher than that in case of the untreated paper sheets.

Table (2): Effect of Addition of Mixture of Carboxymethyl Chitosan (0.5\%) and Cyanoethyl Chitosan $(0.5 \%)$ during Sheet Formation.

\begin{tabular}{|c|c|c|c|c|}
\hline \multirow{2}{*}{$\begin{array}{c}\text { Cyanoethyl : } \\
\text { Carboxymethyl } \\
\text { chitosan }\end{array}$} & \multicolumn{2}{|c|}{ Before aging } & \multicolumn{2}{c|}{$\begin{array}{c}\text { After aging at } 140{ }^{\circ} \mathrm{C} \text { for } 2 \\
\text { hour }\end{array}$} \\
\cline { 2 - 5 } & $\begin{array}{c}\text { Breaking } \\
\text { length (m) }\end{array}$ & Tear factor & $\begin{array}{c}\text { Breaking } \\
\text { length }(\mathrm{m})\end{array}$ & Tear factor \\
\hline $100: 00$ & 4370 & 66.16 & 4240 & 58.22 \\
\hline $80: 20$ & 4166 & 60.89 & 4208 & 59.59 \\
\hline $60: 40$ & 4148 & 63.69 & 4016 & 52.52 \\
\hline $40: 60$ & 4003 & 70.02 & 3984 & 51.00 \\
\hline $20: 80$ & 3912 & 77.82 & 3504 & 51.88 \\
\hline $00: 100$ & 3640 & 85.74 & 4360 & 57.16 \\
\hline
\end{tabular}




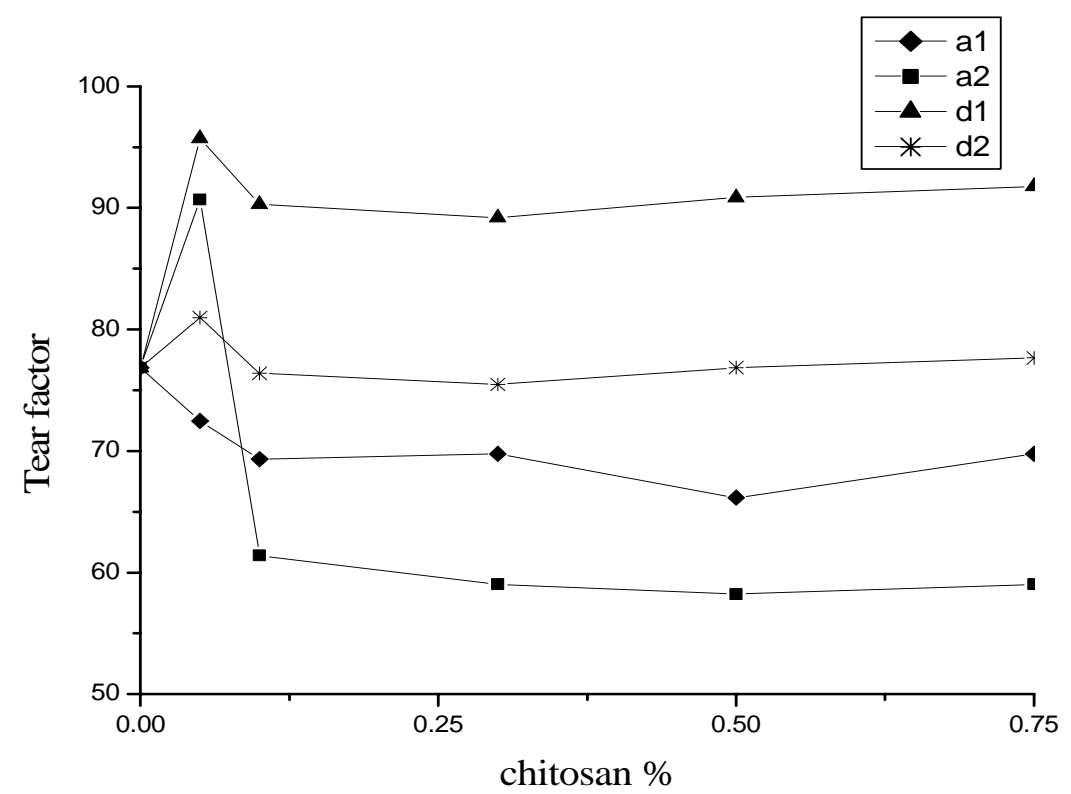

Fig. (5): Effect of Cyanoethyl chitosan \% on tear factor before and after aging.

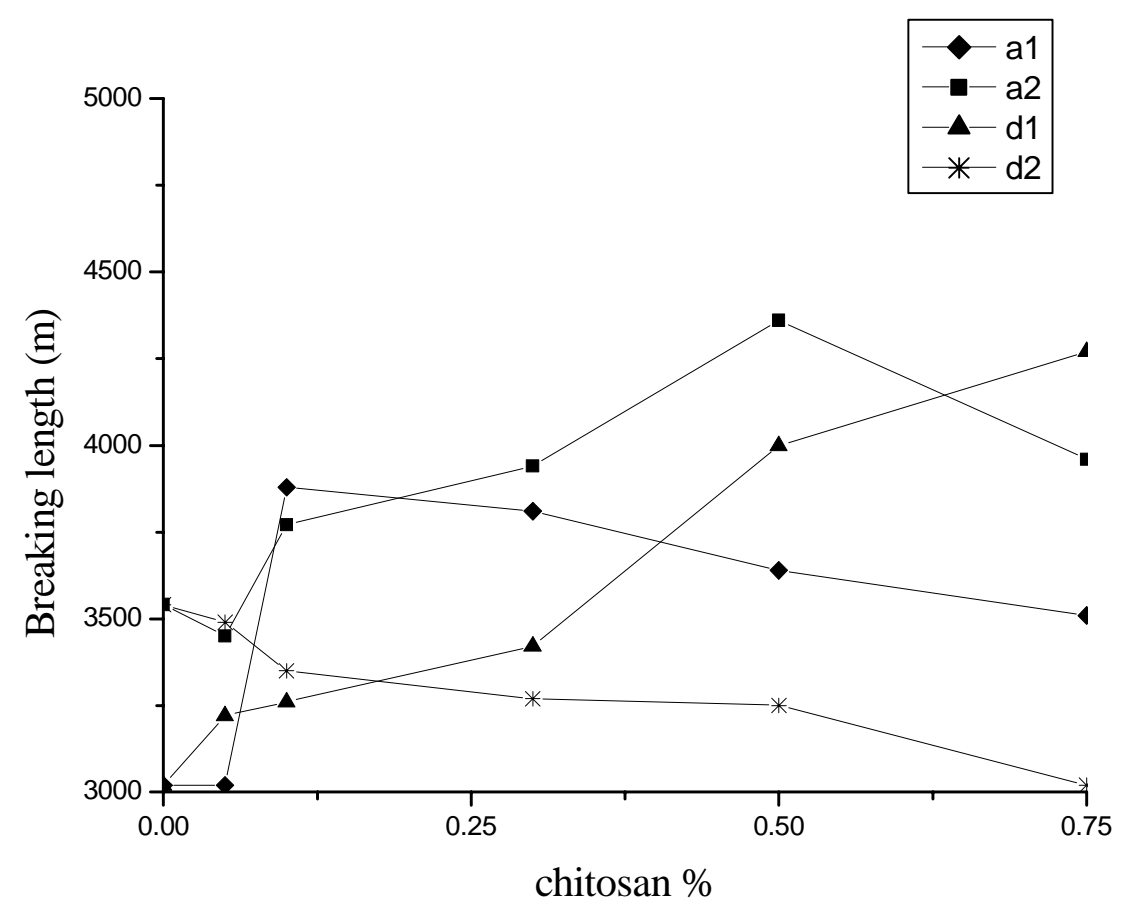

Fig. (6): Effect of carboxymethyl chitosan \% on breaking length before and after aging. 


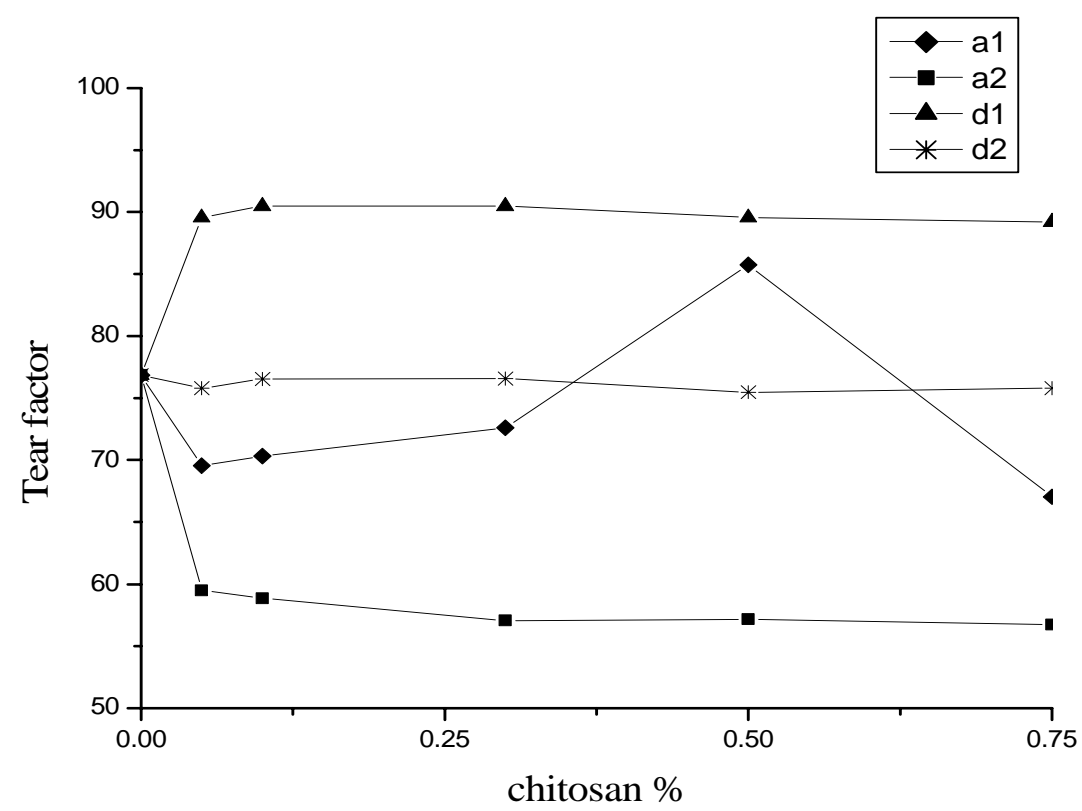

Fig. (7): Effect of carboxymethyl chitosan \% on tear factor before and after aging.

Addition of chitosan or its derivatives increases the mechanical stability of the produced paper sheets Figs. (2-7). From these figures, it is clear that, the aging of treated paper with small amount of chitosan $(0.05 \%)$ at $140{ }^{\circ} \mathrm{C}$ for 2 hours increases the mechanical properties, while the increase in the amount of chitosan causes a decrease in the mechanical properties. This could be attributed to the increase of crosslinking between fiber and chitosan causing stiffness the fiber of the paper and consequently the mechanical properties decrease. In case of treated paper with carboxymethyl and cyanoethyl chitosan, the aging results in an increase in the mechanical properties.

Permittivity $\left(\varepsilon^{\prime}\right)$ and dielectric loss $\left(\varepsilon^{\prime \prime}\right)$ of the untreated paper sheet $\left(\mathrm{S}_{0}\right)$ and that treated by cyanoethyl chitosan as addition method $\left(\mathrm{S}_{\mathrm{a} 1}, \mathrm{~S}_{\mathrm{a} 2}, \ldots, \mathrm{S}_{\mathrm{a} 5}\right)$ were measured over the frequency range from $100 \mathrm{~Hz}$ to $100 \mathrm{kHz}$ at temperature range from 20 to $140{ }^{\circ} \mathrm{C}$. The data obtained for $\varepsilon^{\prime}$ and $\varepsilon^{\prime \prime}$ vs. frequency, for the paper sheets under investigation at different temperatures are illustrated graphically in Fig. (8). From this figure, it is clear that $\varepsilon^{\prime}$ decreases by the increasing temperature. This trend going on by the addition of cyanoethyl chitosan till concentration of $0.3 \%\left(S_{a 3}\right)$ then starts to reverse this trend. Fig. (9). Illustrates such behavior by showing the variation of $\varepsilon^{\prime}$ vs cyanoethyl chitosan content at three different frequencies. An intersecting point could be noticed at approximately $0.2 \%$. The variation of $\varepsilon^{\prime}$ with temperature 
could be explained in the view of the polar groups mobility [20]. At lower content (less than $0.2 \%$ ) the decrease of $\varepsilon^{\prime}$ with temperature may be explained by the increase in the cross linking with cyanoethyl chitosan. At contents higher than $0.2 \%$, the increase of $\varepsilon^{\prime}$ with temperature may be explained by the increase in the polar groups mobility, the decrease in density, and, hence, a decrease in the effect of the environment that facilitates the orientation of the mobile groups [20]. Around the content of $0.2 \%$, an equilibrium state between the two phenomena could be noticed. It is evident also that $\varepsilon^{\prime}$ decreases with increasing frequency and shows an anomalous dispersion.

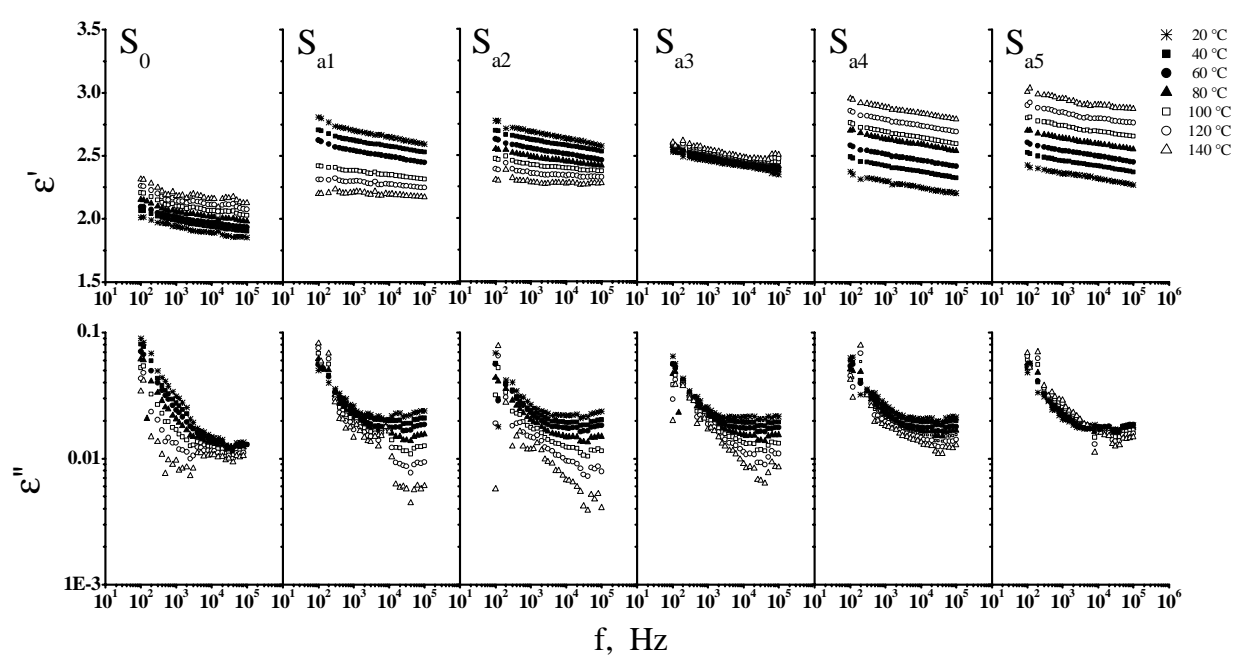

Fig. (8): Permittivity $\varepsilon$ ' and dielectric loss $\varepsilon$ " versus frequency (f) of the untreated paper sheet $\left(\mathrm{S}_{0}\right)$ and that treated by Cyanoethyl chitosan as addition method $\left(\mathrm{S}_{\mathrm{a} 1}\right.$, $\left.\mathrm{S}_{\mathrm{a} 2}, \ldots, \mathrm{S}_{\mathrm{a} 5}\right)$ at temperatures $* 20^{\circ} \mathrm{C}, 40^{\circ} \mathrm{C},-60^{\circ} \mathrm{C}, \Delta 80^{\circ} \mathrm{C}$, $\square 100^{\circ} \mathrm{C}, \circ 120^{\circ} \mathrm{C}$ and $\triangle 140^{\circ} \mathrm{C}$.

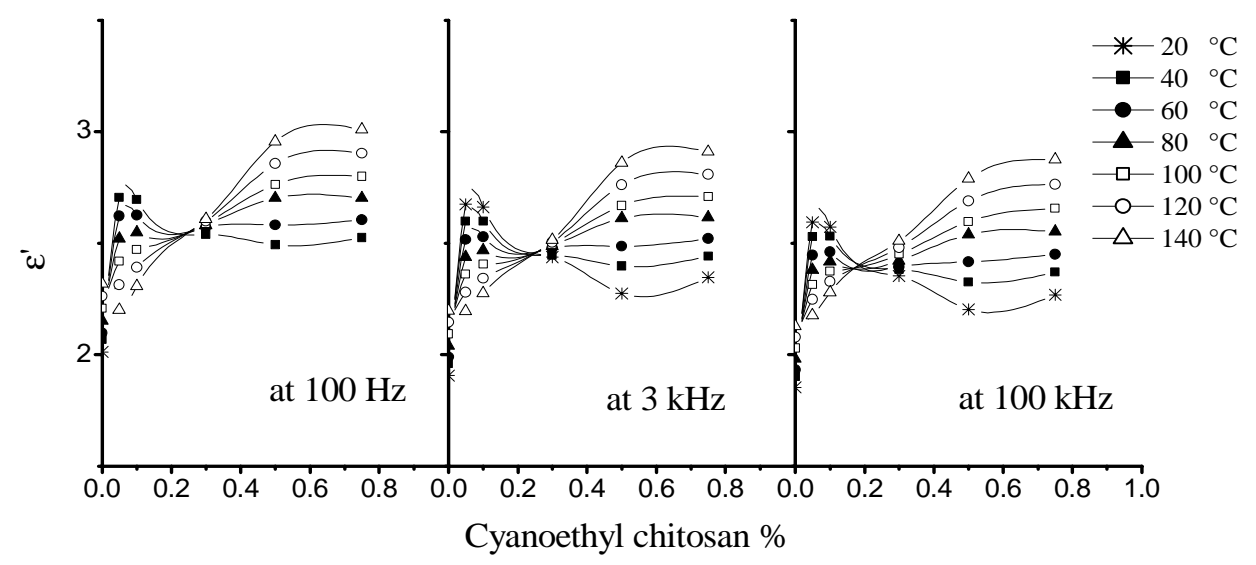

Fig. (9): Permittivity $\varepsilon$ ' versus addition percent of Cyanoethyl chitosan. 
Also from Fig. (8), it is apparent that $\varepsilon^{\prime \prime}$ is decreased at higher temperatures, especially in the higher-frequency range. Moreover, the value of $\varepsilon$ " in the lower-frequency range is slightly affected by the addition of cyanoethyl chitosan to sample $S_{0}$ and approximately the same for samples under investigation. From the same Figure, it is clear that the curves relating $\varepsilon$ " and $\log$ $f$ are broader than Debye curves [24], indicating that more than one relaxation process is present. Fitting of the data at $60{ }^{\circ} \mathrm{C}$ is performed by a computer program based on all the different spectral functions commonly used in dielectric research such as Debye [25], Cole-Cole [26], Cole-Davidson [27], HavriliakNegami [24], Fröhlich [20] and Rocard-Powles [24]. The best fitting of the data was done by a superposition of Fröhlich and Havriliak-Negami functions in addition to the conductivity term. On other words, the spectral function $\varepsilon^{\prime \prime}(\omega)$ could be expressed as:

$$
\varepsilon^{\prime \prime}(\omega)=\varepsilon^{\prime \prime}(\omega)_{F r}+\varepsilon^{\prime \prime}(\omega)_{H N}+\frac{\theta \sigma}{\omega}
$$

has been used to analytically represent the measured spectra. $\mathcal{E}^{\prime \prime}(\omega)_{F r}$ denotes Fröhlich function form, $\varepsilon^{\prime \prime}(\omega)_{H N}$ denotes Havriliak-Negami function, $\omega$ is the angular frequency, $\sigma$ is dc conductivity, and $\theta$ is a constant which equals $4 \pi\left(9 \times 10^{11}\right)$. Fröhlich and Havriliak-Negami functions are represented as:

$$
\mathcal{E}^{\prime \prime}(\omega)_{F r}=\frac{\mathcal{E}_{s}-\varepsilon_{\infty}}{P} \arctan \left[\frac{\sinh \mathrm{P} / 2}{\cosh \ln \left(\omega \bar{\tau}_{F r}\right)}\right]
$$

where $\mathrm{P}$ is a parameter describing the width of the distribution of relaxation times and equals $\ln \left(\tau_{1} / \tau_{2}\right), \bar{\tau}_{F r}$ is the mean relaxation time and equals $\left(\tau_{1} \tau_{2}\right)^{1 / 2} \cdot \varepsilon_{s}$ and $\varepsilon_{\infty}$ are the static permittivity and the permittivity at infinite frequency, respectively.

$$
\varepsilon^{\prime \prime}(\omega)_{H N}=\frac{\left(\varepsilon_{s}-\varepsilon_{\infty}\right) \sin \Phi \beta}{\left[1+2\left(\omega \tau_{H N}\right)^{1-\alpha} \sin \pi \alpha / 2+\left(\omega \tau_{H N}\right)^{2(1-\alpha)}\right]^{\beta / 2}}
$$

where $\alpha$ and $\beta$ are Havriliak-Negami distribution parameters and $\Phi$ represented as

$$
\Phi=\arctan \frac{\left(\omega \tau_{H N}\right)^{1-\alpha} \cos \pi \alpha / 2}{1+\left(\omega \tau_{H N}\right)^{1-\alpha} \sin \pi \alpha / 2}
$$


An example of the dielectric spectrum and the fitting of the data for the paper sheet treated by cyanoethyl chitosan $(0.5 \%)$ as addition method at $60{ }^{\circ} \mathrm{C}$ is illustrated graphically in Fig. (10). Relaxation parameters obtained according to that fitting are given in Table (5). The width of the distribution of relaxation times $P$ is around 2. Also, the Havriliak-Negami distribution parameters $\alpha$ and $\beta$ are equal to 0.5 and 0.66 respectively for this fitting. The first absorption region which lies approximately at $f \approx 0.21 \mathrm{kHz}$ is found to be present for all the samples investigated. Those low-frequency losses may be attributed to MaxwellWagner losses arising from the interfacial polarization caused by the multiconstituents of the investigated systems. The difference in permittivities and conductivities in the constituents of the investigated materials is considered to be the reason for the presence of such effect.

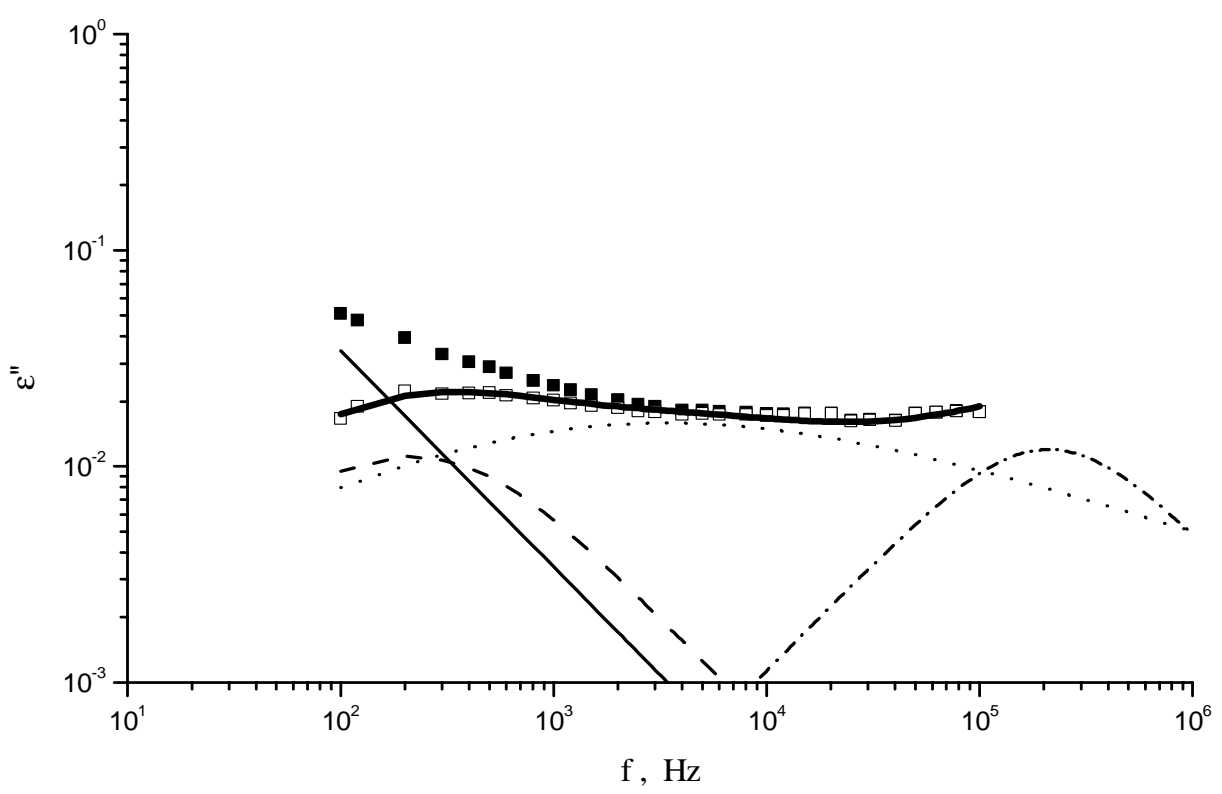

Fig. (10): The absorption curve of the paper sheet which treated by Cyanoethyl chitosan $(0.5 \%)$ as addition method at $60 \mathrm{oC}$. The data fitted by Frohlich $(---)$, havriliak-Negami (....), Debye (-...) and the dc conductivity $(-)$. Experimental data ( $\mathbf{(})$, dielectric loss after subtraction of conductivity (口), Total fit ( $\longrightarrow$ ).

The second absorption region, which is found to be higher when the cyanoethyl chitosan is added to the paper sheet, could be attributed to the orientation of the large aggregates caused by movement of the main chain that are expected to be formed by the addition of cyanoethyl chitosan to the paper sheet $[21,28]$. 
In order to get the best fit for the given spectra, a third relaxation time that lies on the order of $10^{-7} \mathrm{~s}$ could be suggested. Unfortunately, we cannot give further accuracy of this region since we have no measurement over 100 $\mathrm{kHz}$. May be this relaxation time associated with those orientations of small aggregates is caused by the movement of the main chain $[21,28]$.

\subsection{Chitosan and its derivatives as solution for paper sheet dipping:}

In another trial, paper sheets were soaked in solutions containing chitosan and also its derivatives in different concentrations. The paper sheets were dipped in different concentrations of chitosan solution and also its derivatives for 30 second. After dipping, the paper sheets were pressed between two filter paper sheets to remove the excess polymer, and then dried on drum at $105{ }^{\circ} \mathrm{C}$ for 2 hours. Table (3) shows the retained amount of chitosan and its derivatives on paper sheet after dipping where its seen that the retained polymer increases by increasing the concentration of dipping solution while it is nearly the same for chitosan or is derivatives for the same concentration.

Table (3): Retained Amount on Paper Sheets After Dipping.

\begin{tabular}{|c|c|c|c|}
\hline $\begin{array}{c}\text { Concentration of } \\
\text { dipping solutions } \\
\%\end{array}$ & \multicolumn{3}{|c|}{ Retained $\left(\mathrm{g} / \mathrm{m}^{2}\right)$} \\
\cline { 2 - 4 } & Chitosan & $\begin{array}{c}\text { Cyanoethyl } \\
\text { chitosan }\end{array}$ & $\begin{array}{c}\text { Carboxymethyl } \\
\text { chitosan }\end{array}$ \\
\hline 0.05 & 0.06 & 0.05 & 0.06 \\
\hline 0.10 & 0.12 & 0.11 & 0.11 \\
\hline 0.30 & 0.32 & 0.36 & 0.36 \\
\hline 0.50 & 0.57 & 0.60 & 0.60 \\
\hline 0.75 & 0.79 & 0.85 & 0.87 \\
\hline
\end{tabular}

From Figs. (2-7), it is clear that, the breaking length of the treated paper sheets by dipping in chitosan or its derivatives slightly increases while the tear factor was slightly increases. This could be attributed to the formation of a coaled layer on the surface of paper sheets causing an increase in the bonding strength between the fibers of paper sheets on the surface. This causes a high increase in the breaking length and slight increase in the tear factor. From Figs. (4-7), it could be seen that a mechanical improvement in paper sheets increases by increasing the added amount of chitosan derivatives and the maximum improvement is reached at quantities of cyanoethyl and carboxymethyl chitosan about $0.5 \%$. Increasing the added amount higher than $0.5 \%$ decreases the mechanical properties of the produced paper sheets.

A dipped paper sheet in carboxymetyl chitosan solution has higher mechanical properties as compared with chitosan or cyanoethyl chitosan solution. This may be due to the higher binding between paper sheets fiber 
rather than the other two materials. Thus cross-linking between fibers increases the adhesion between fiber and consequently the mechanical properties. The mechanical properties of the dipped paper sheets in carboxymethyl chitosan solution increase by increasing the concentration of the dipped solution, i.e. increase of the retained polymer in paper sheets.

Aging at $140{ }^{\circ} \mathrm{C}$ for 2 hours of the paper sheets previously treated by soaking has slight effect on the mechanical properties of the paper sheets (see Table (4)). Aging increases the breaking length for the small retained polymer, and breaking decreases for paper sheets of high retained polymer. The tear factor decreases by aging in case of all retained polymer. This is due to the hardness on the surface of the polymer causing a cracking of the fiber and the mechanical properties decrease.

Table (4): Effect of Dipping of Paper Sheets in a mixture of Carboxymethyl Chitosan $(0.5 \%)$ and Cyanoethyl chitosan $(0.5 \%)$.

\begin{tabular}{|c|c|c|c|c|c|}
\hline \multirow{2}{*}{$\begin{array}{c}\text { Cyanoethyl : } \\
\text { Carboxymethyl } \\
\text { chitosan }\end{array}$} & $\begin{array}{c}\text { Retained } \\
\left(\mathrm{g} / \mathrm{m}^{2}\right)\end{array}$ & \multicolumn{2}{|c|}{ Before aging } & \multicolumn{2}{c|}{$\begin{array}{c}\text { After aging at } 140{ }^{\circ} \mathrm{C} \\
\text { for } 2 \text { hour }\end{array}$} \\
\cline { 3 - 6 } & $\begin{array}{c}\text { Breaking } \\
\text { length }(\mathrm{m})\end{array}$ & $\begin{array}{c}\text { Tear } \\
\text { factor }\end{array}$ & $\begin{array}{c}\text { Breaking } \\
\text { length }(\mathrm{m})\end{array}$ & $\begin{array}{c}\text { Tear } \\
\text { factor }\end{array}$ \\
\hline $100: 00$ & 0.60 & 3150 & 90.85 & 3490 & 76.87 \\
\hline $80: 20$ & 0.54 & 3184 & 82.53 & 3558 & 82.55 \\
\hline $60: 40$ & 0.59 & 3255 & 77.11 & 3778 & 80.04 \\
\hline $40: 60$ & 0.55 & 3322 & 77.10 & 3599 & 77.81 \\
\hline $20: 80$ & 0.55 & 3699 & 73.79 & 3367 & 79.04 \\
\hline $00: 100$ & 0.60 & 4000 & 89.57 & 3250 & 75.47 \\
\hline
\end{tabular}

Comparing the mechanical properties of the treated paper sheets with chitosan and its derivates added during sheet formation with that resulting from dipping in chitosan and its derivates, it is seen that, the breaking length of the first is higher than that in the second treatment, while tear factor of the second is higher than that in the first.

For untreated paper sheet $\left(\mathrm{S}_{0}\right)$ and that treated by dipping in cyanoethyl chitosan solution $\left(\mathrm{S}_{\mathrm{d} 1}, \mathrm{~S}_{\mathrm{d} 2}, \ldots, \mathrm{S}_{\mathrm{d} 5}\right)$ permittivity $\left(\varepsilon^{\prime}\right)$ and dielectric loss $\left(\varepsilon^{\prime \prime}\right)$ were measured over the frequency range from $100 \mathrm{~Hz}$ to $100 \mathrm{kHz}$ at temperature range from 20 to $140{ }^{\circ} \mathrm{C}$. The data obtained for $\varepsilon^{\prime}$ and $\varepsilon^{\prime \prime}$ vs. frequency for the paper sheets under the investigation at different temperatures are illustrated graphically in Fig. (11). 


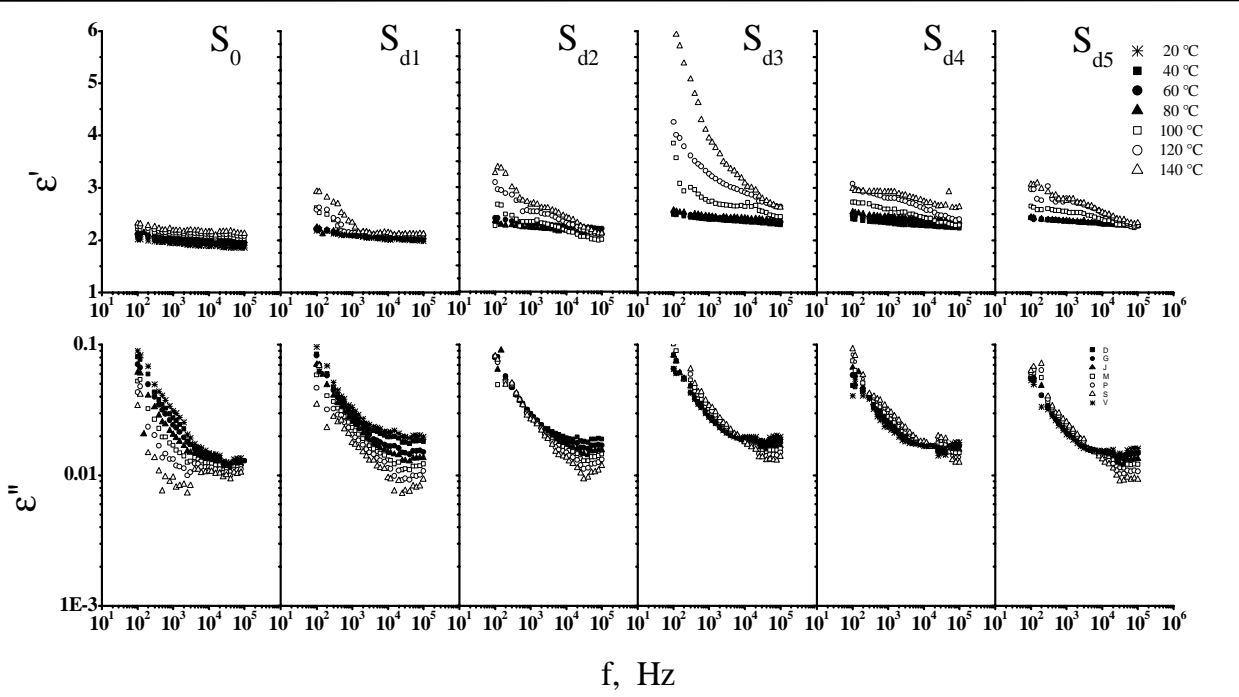

Fig. (11): Permittivity $\varepsilon^{\prime}$ and dielectric loss $\varepsilon$ " versus frequency (f) of the untreated paper sheet $\left(\mathrm{S}_{0}\right)$ and that treated by Cyanoethyl chitosan as addition method $\left(\mathrm{S}_{\mathrm{d} 1}, \mathrm{~S}_{\mathrm{d} 2}, \ldots, \mathrm{S}_{\mathrm{d} 5}\right)$ at temperatures $* 20^{\circ} \mathrm{C}, 40^{\circ} \mathrm{C}, \bullet 60^{\circ} \mathrm{C}, \boldsymbol{\Delta} 80^{\circ} \mathrm{C}$, $100^{\circ} \mathrm{C}, \circ 120^{\circ} \mathrm{C}$ and $\Delta 140^{\circ} \mathrm{C}$.

It is clear that $\varepsilon^{\prime}$ increases with increasing temperature and decreases with increasing frequency. Similar behavior was noticed before [20]. The increase of $\varepsilon^{\prime}$ with temperature can be explained by the increase in the mobility of polar groups, the decrease in density, and, hence, a decrease in the effect of the environment that facilitates the orientation of the mobile groups. The decrease of $\varepsilon^{\prime}$ with frequency shows an anomalous dispersion.

Moreover, Fig. (11) shows that for sample $S_{0}$ dipped in different concentrations of cyanoethyl chitosan the value of $\varepsilon^{\prime}$ increases till concentration of $0.3 \%\left(\mathrm{~S}_{\mathrm{d} 3}\right)$ then starts to decrease. This trend is clear at higher temperatures. Such behavior is clear in Fig. (12) which shows the variation of $\varepsilon^{\prime}$ vs cyanoethyl chitosan content at different temperatures and three different frequencies .

It is apparent also from Fig. (11) that $\varepsilon^{\prime \prime}$ decreased at higher temperatures, especially in the higher-frequency region. Moreover, the value of $\varepsilon^{\prime \prime}$ in the lower-frequency region is slightly affected by the cyanoethyl chitosan content for samples under investigation. The dielectric spectra were fitted by a superposition of Fröhlich and Havriliak-Negami functions in addition to the conductivity term. Relaxation parameters obtained according to that fitting are given in Table (5). The width of the distribution of relaxation times $P$ is around 2. Also, the Havriliak-Negami distribution parameters $\alpha$ and $\beta$ are equal to 0.5 and 0.66 respectively for this fitting. 


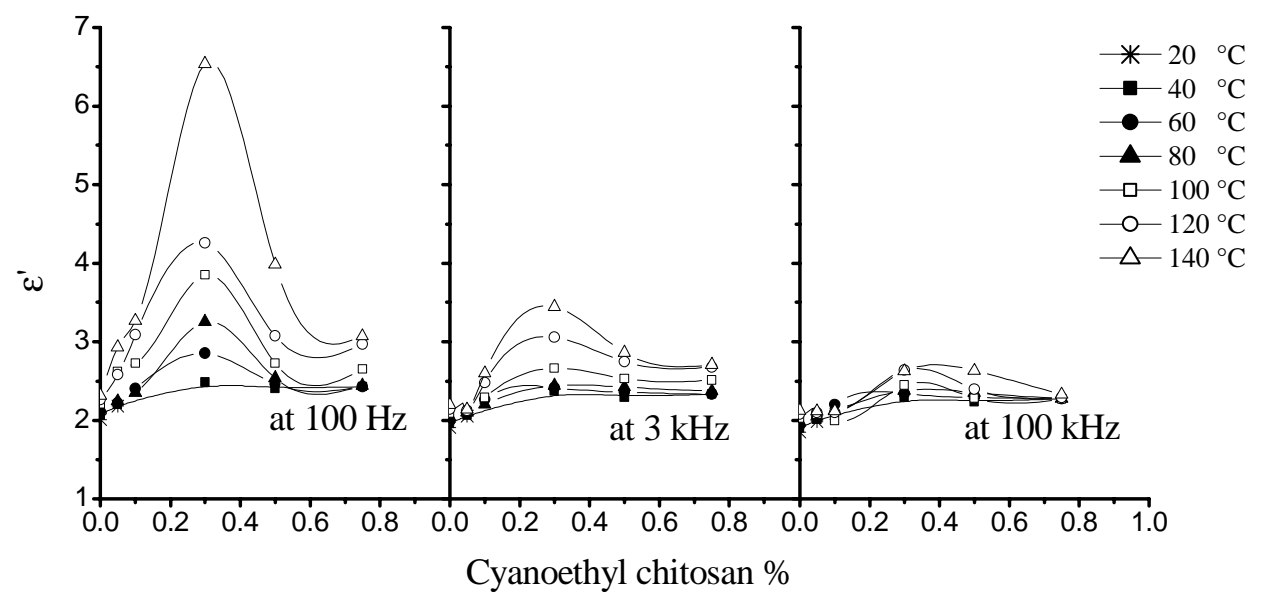

Fig. (12): Permittivity e' versus percent of Cyanoethyl chitosan as dipping solution.

Table (5): Relaxation Parameters of Untreated Paper Sheet and that Treated by Cyanoethyl chitosan.

\begin{tabular}{|c|c|c|c|}
\hline Sample & $\boldsymbol{\tau}_{\mathbf{1}} \mathbf{x 1 0}(\mathbf{s})$ & $\boldsymbol{\tau}_{\mathbf{2}} \mathbf{x} \mathbf{1 0}^{\mathbf{5}}(\mathbf{s})$ & $\boldsymbol{\sigma} \mathbf{x} \mathbf{1 0}^{\mathbf{1 2}}\left(\boldsymbol{\Omega}^{\mathbf{- 1}} \mathbf{c m}^{\mathbf{- 1}}\right)$ \\
\hline $\mathrm{S}_{0}$ & 7.073 & 2.924 & 3.232 \\
\hline $\mathrm{S}_{\mathrm{a} 1}$ & 7.604 & 8.355 & 2.123 \\
\hline $\mathrm{S}_{\mathrm{a} 2}$ & 7.604 & 9.314 & 2.123 \\
\hline $\mathrm{S}_{\mathrm{a} 3}$ & 7.645 & 10.380 & 2.048 \\
\hline $\mathrm{S}_{\mathrm{a} 4}$ & 7.645 & 10.760 & 1.905 \\
\hline $\mathrm{S}_{\mathrm{a} 5}$ & 7.784 & 11.570 & 1.837 \\
\hline $\mathrm{S}_{\mathrm{d} 1}$ & 7.073 & 3.189 & 2.963 \\
\hline $\mathrm{S}_{\mathrm{d} 2}$ & 7.604 & 3.633 & 2.736 \\
\hline $\mathrm{S}_{\mathrm{d} 3}$ & 7.685 & 3.906 & 2.202 \\
\hline $\mathrm{S}_{\mathrm{d} 4}$ & 7.604 & 4.050 & 2.123 \\
\hline $\mathrm{S}_{\mathrm{d} 5}$ & 7.334 & 4.050 & 2.048 \\
\hline
\end{tabular}

$\tau_{1}$ is Fröhlich relaxation time, $\tau_{2}$ is Havriliak-Negami relaxation time and $\sigma$ is the conductivity.

The low-frequency losses may be due to the Maxwell-Wagner effect [21] as a result of the interfacial polarization caused by the multiconstituents of the investigated systems. The second absorption region, is found to be slightly the same as the paper sheet $S_{0}$. This result could confirm that this relaxation time could be attributed to the orientation of the large aggregates caused by movement of the main chain that are expected to be formed by the addition of cyanoethyl chitosan to the paper sheet $[21,28]$. 


\section{Conclusions:}

- Addition of chitosan and also its derivatives achieve an improvement in the strength properties of unagged and aged paper sheets.

- Additions of mixture of cyanoethyl and carboxymethyl chitosan improve the mechanical properties of the produced paper sheets.

- Values of breaking length of treated paper sheets with chitosan and also its derivatives by addition during sheet formation are higher as compared with those obtained with dipping in chitosan and also its derivatives. On the other hand values of tear factor for treated paper sheet with dipping are higher as compared with those obtained with addition method.

- Additions of cyanoethyl chitosan improve the dielectric properties of the treated paper sheets.

\section{References:}

1. A. M. Olsson and L. Salmen, Carbohydrate Res. 339 (4), 813 (2004).

2. L. Gardlund, L. Wagberg and R. Gernandt, Colloids and Surfaces A: hysicochem. Eng. Aspects 218 (1-3), 137 (2003).

3. R. Gernandt, L. Wagberg L. Gardlund and H. Dautzenberg, Colloid Surface A 213 (1), 15 (2003).

4. A. M. A. Nada and H. El. Saied, Polym. Plast. Technol and Eng. 28, 787 (1989).

5. A. M. A. Nada, M.H. Abo-Shosha and N. A. Ibraheim, Polym. Plast. Technol and Eng. 35, 355 (1996).

6. A. M. A. Nada and M.H. Ayoub, Elastomers and Plastics 29, 11(1997).

7. M. H. Aboshosha, N.A. Ibrahim, and A. M. A. Nada, Science Int. J. (Lahore) 8, 251 (1996).

8. A. M. A. Nada, M. El- Sakhawy and A. Abd-Elhakime, $4^{\text {th }}$ Arab Int. Con. Polym. Sci. and Technol., Cairo, Egypt. Sept. 7-11 (1997).

9. A. M. A. Nada, S. Kamel, and M. El-Sakhawy, Restaurater. 21, 238 (2000).

10. M. Mucha, React. Func. Polym. 38, 19 (1998).

11. T. Ikejima, K. Yagi and Y. Inoue, Macromol. Chem. and Phys. 200(2), 413 (1999).

12. Y. Shignemasa and S. Minami, In chitin/chitosan, "Handbook of Chitin and Chitosan", Ghodo Publishing Co. Japan Soc. Tokyo, p178 (1995).

13. R. A. A. Muzzarelli, Cell Mol. Life Sci. 53, 137 (1997).

14. Z. Zang, Y. Kimura, M. Takahashi and H. Yamane, Polymer 41(3), 899 (2000). 
15. J. Einfeldt, D. Meißner, A. Kwasniewski, J. Non-Cryst. Solids 320, 44 (2003).

16. J. Einfeldt, D. Meißner, A. Kwasniewski, Cellulose 11(2), 137 (2004).

17. A.M.A. Nada, M. Dawy, A.H. Salama, Materials Chem. and Phys. 84, 205, (2004).

18. J. Einfeldt, T. Heinze, T. Liebert and A. Kwasniewski, Carbohydrate Polym. 49 (3), 357 (2002).

19. F. Correia, D. N. Roy and W. Chute, Pulp \& Paper-Canada 104 (5), 51 (2003).

20. A. L. G. Saad, A. M. Hassan, M. A. Youssif and M. G. M. Ahmed, J. Appl Polym Sci. 65, 27 (1997).

21. D. E. E. Nashar, S. L. Abd-El-Messieh and A. H. Basta, J. Applied Polymer Science 91, 469 (2004).

22. S. Kokot, B. Czarnik- Matusewicz and Y. Ozaki, Biopolymers 67 (6), 456 (2002).

23. M. Mucha and D. Miskiewicz. J. Appl. Polym. Sci. 77, 3210 (2000).

24. N. G. Mc-Crum, B. E. Read and G. Williams, "Anelastic and dielectric effects in polymeric solids" Dover edition, Dover Inc., New York (1991).

25. P. Q. Mantas, J. EUR. Ceram. Soc. 19 (12), 2079 (1999).

26. V. A. Stephanovich, M. D. Glinchuk and B. Hilczer, Ferroelectrics 240 (1-4), 1495 (2000).

27. T. Blochowicz, C. Tschirwitz, S. Benkhof and E. A. Rossler, J. Chem. Phys. 118 (16), 7544 (2003).

28. S. L. Abd-el-Messieh, M. G. Mohamed, A. M. Mazrouaa and A. Soliman, J. App. Polymer Sci. 85, 271 (2002). 